\title{
THE CLASSIFICATION OF THE CAUSES OF BLINDNESS
}

BY

\author{
A. F. MacCallan, C.B.E.
}

THE preparation of a scheme for the classification of the causes of blindness which can be adopted internationally is a very important matter. It is also a very difficult one for two reasons, first because a scheme of classification is already in use in some countries, and secondly because the same definition of blindness is not universal.

It is understood that what is being considered is a scientific classification for the use of ophthalmic surgeons, and not a scheme for the registration of those who have so little visual acuity as to need, if children, a special form of education, or if adults, financial assistance to enable them to earn a living or to exist without misery.

It is therefore necessary to include in the classification cases of monocular blindness, for if this is not done the ocular disasters which may result from war, from following certain trades, from engaging in certain sports and from birth injuries will be omitted. This was referred to in the interesting scheme of classification which was drawn up by Professor Marquez and presented to the XIV International Congress of Ophthalmology.

The loss of the sight of one eye is not of insuperable disadvantage to a banker or a stock-broker or a grocer, but to a bricklayer or a chauffeur or an ophthalmic surgeon it may be the cause of the loss of his livelihood.

In a country where there has been for many years a well-understood definition of blindness and scheme of classification it is undesirable that these should be changed. I instance Egypt where a quarter of a century ago I adopted Trousseau's definition “inability to count figures at a distance of one metre." The scheme of classification which I arranged is shown in the annex as well as the statistics for the years 1908 and 1932. These refer to patients who were blind in either one or both eyes.

It is seen from these statistics that the incidence of blindness in one or both eyes among patients presenting themselves for treatment at the Ophthalmic Hospitals of Egypt has been reduced in a period of 25 years from approximately 13 per cent. to approximately 7 per cent.

If I were arranging a system of classification for Egvpt at the present time I should make some changes in the schedule, nevertheless I consider that there is a great advantage in retaining a 
classification by which the amount of blindness in the country can be gauged from year to year, and which is not too complicated for compilation by the medical officers.

Three different systems of classification of the causes of blindness have been brought to my notice, and there may be others with which I am unacquainted. These are (1) that of Professor van Duyse, (2) that of Professor Marquez, and (3) that contained in the Report of the Prevention of Blindness Committee, London, 1931 .

I am sure we are all greatly indebted to Professor van Duyse for the trouble he has taken and for the high scientific ability he has shown in the scheme of classification he has proposed. I think for a detailed scheme it would be difficult to arrange anything more all-embracing. However I do not think that hospital medical officers would have the time or patience to carry it out. With the brief classification I am not so entirely satisfied.

The scheme proposed by Professor Marquez seems to be highly original and useful. As regards inscription it can be carried out quite well by any ophthalmic surgeon, but in the preparation of statistics at the end of a year, the services of highly expert persons would be required.

I must give my opinion that up to the present the classification already adopted by the Prevention of Blindness Committee in London is the most useful for my own country at any rate.

\section{BIBLIOGRAPHY}

Park Lewis (1924).-The prevention of blindness as an organized movement. Trans. Ophthal. Soc. U.K., Vol. XLIV, p. 326.

(1925).-The scope and possibilities of preventive measures in ophthalmology. Trans. Ophthal. Soc. U.K., Vol. XLV, p. 802.

Red Cross (1929). - The prevention of blindness. League of Red Cross Societies. 2 Avenue Velasquez, Paris, 1929.

League of Nations (1929).-Report on the welfare of the blind. League of Nations Publications. III. Health, Vol. III, p. 8, 1929.

Cridland (1930).-Comments on the certified causes of blindness, Trans. Ophthal. Soc. U.K., Vol. L, p. 337.

Graham (1932).-Certification of blindness. Trans. Ophthal. Soc. U.K., Vol. LII, p. 289.

Prevention of Blindness Committee (1931).-Certification of blindness, etc.

(1933).--Report on hereditary blindness. (Prevention of Blindness Committee, 66, Victoria Street, London, S.W.1.)

Marquez (1933).-Need of classification of the causes of blindness. XIV International Congress of Ophthalmology. Reports, Vol. IV, p. 371. 
CAUSES OF BLINDNESS

At The Ophthalmic Hospitals of Egypt

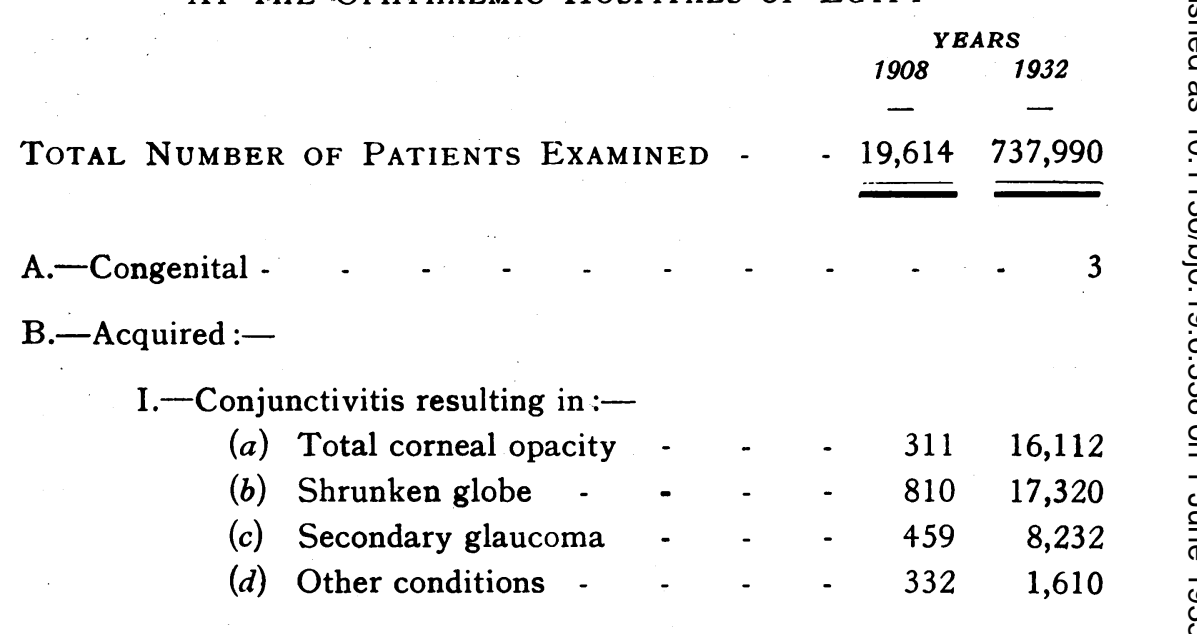

II.-Fundus :-

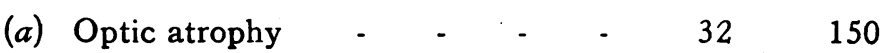

(b) Optic neuritis and papilloedema $\quad-\quad-\quad 19$

(c) Retinitis pigmentosa - - $\quad$ - $4 \quad 4 \quad 41$

(d) Detachment of retina - $\quad$ - $\quad$ - $\quad-63$

(e) Other diseases of fundus - $\quad$ - $34 \quad 205$

III.-Glaucoma, primary :-

(a) Monocular - - - - $\quad$ - $131 \quad 3,007$

(b) Binocular - - - - - $253 \quad 2,290$

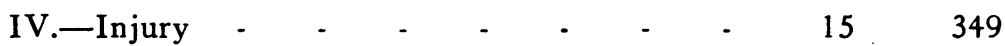

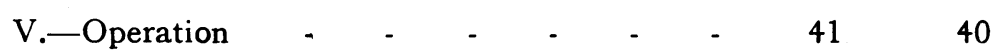

VI.-Infectious diseases -

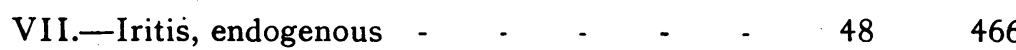

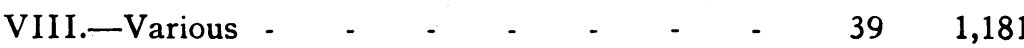

